\title{
Urology Amidst the War on COVID-19
}

\author{
Bishoy Hanna, $₫ 1,2$ Stuart Jackson, ${ }^{1,3}$ Harry Narroway, ${ }^{3,4}$ Amanda Chung 2,5,6 \\ ${ }^{1}$ Nepean Urology Research Group, Nepean Hospital, Kingswood, Australia ${ }^{2}$ North Shore Urology Research Group, St Leonards, Australia ${ }^{3}$ University of Sydney, \\ Camperdown, Australia ${ }^{4}$ Central Coast Local Health District, Gosford Hospital, Gosford, Australia ${ }^{5}$ Department of Urology, Macquarie University Hospital, Macquarie \\ University, Australia ${ }^{6}$ Department of Urology, University of Sydney, Concord Repatriation General Hospital, Concord, Australia
}

\section{Abstract}

Objectives We sought to review the impact of the COVID-19 pandemic on the practice of urology internationally, with particular focus on the Australian response.

Methods A literature search of PubMed was conducted using search terms "urology," "coronavirus," "COVID-19," and "surgery." This generated 165 articles. The abstracts were reviewed for relevance, and 33 articles were selected, reviewed in depth, and information synthesised along with relevant government, surgical college, and urological society policy documents.

Results Extensive health care changes have been implemented worldwide to curb infection rates. Elective surgery cancellations have been widely mandated to curb infection rates with mixed success. Whilst demand on hospital resources was reduced by up to $80 \%$, the estimated cost to clear the surgical backlog in the UK has reached $£ 100$ million. Strict perioperative precautions have also been employed with mandatory personal protective equipment for all surgical staff and guidelines fast tracked for safe aerosol-generating procedures. Attempts to reduce exposure to patients and health care workers resulted in compromised operative time, blood loss, and length of hospital stay, with potential increased risk of short- and long-term complications. Systemic changes to education and training have also been made. Clinically, the cancellation of training examinations and a freeze on rotations and elective surgery restrictions have blunted surgical experience and teaching. The effect has rippled through junior doctor positions, with uncertainty remaining for training positions in 2021.

Conclusions The COVID-19 pandemic is the greatest current challenge facing health care worldwide. Amidst elective surgery restrictions, novel preoperative testing procedures and intraoperative precautions, providing safe and appropriate urological care is a major challenge. This review was derived entirely from expert opinion articles. Further research into the virus is needed to bring the world safely through the pandemic, and post-pandemic recovery will likely be the next challenge.

\section{Introduction}

The first reported cases of coronavirus disease 2019 (COVID-19), which is caused by severe acute respiratory syndrome coronavirus 2 (SARS-CoV-2), originated in Wuhan City, Hubei Province, China in December 2019[1]. The virus spread rapidly around the world and was declared a pandemic by the World Health Organisation (WHO) on March 11, 2020. At that time there were 118000 cases in 114 countries with 4291 lives lost[2]. The exponential nature of the infection meant that by February 2021, there were 104.4 million reports cases worldwide with 2.3 million deaths[3]. Figure 1 shows the growth in COVID-19 deaths to the time of writing.

\section{Key Words}

Urology, COVID-19, coronavirus, pandemic

\section{Competing Interests}

$$
\text { None declared. }
$$

\section{Article Information}

Received on September 27, 2020

Accepted on February 8, 2021

Soc Int Urol J. 2021;2(2):120-128

DOI: https://10.48083/00BF6912 
FIGURE 1.

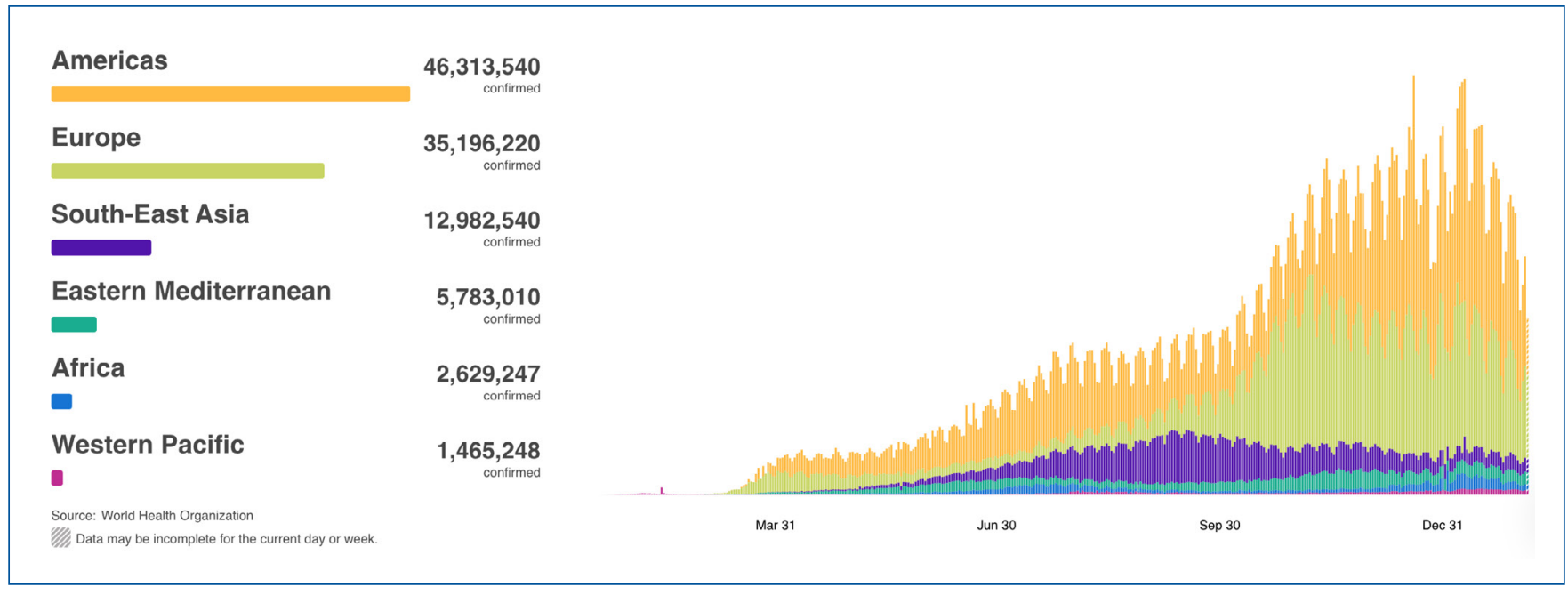

The impact of this pandemic is widespread. Internationally, governments face the challenge of imposing lockdowns, social distancing measures, personal protective equipment laws, and health care resource allocation to curb infection rates. Given the unprecedented nature of the pandemic, policies are often guided by expert opinion in the absence of highlevel evidence base with potentially enormous economic consequences. Measures have had varied success worldwide.

Health care administration is at the forefront of the COVID-19 response. Consequently, the global urological community grapples with maintaining patient safety by balancing potential delays in diagnosis and treatment of urological conditions against risks of COVID-19 exposure and additional stress on health care resources. Table 1 outlines the deferral protocols for urological surgeries at the height of pandemic restrictions. So far, the response has been relatively successful in Australia and New Zealand, with 10 and 4 COVID-19 deaths per 1 million people respectively; however, Australians are acutely aware that the COVID-19 pandemic is far from over as one of the Australian states, Victoria, is coming out of a "second wave" of the infection. At the time of writing of this article, by way of comparison, the statistics abroad are 475 deaths per million in the United States of America, and 230 deaths per million in Europe[3]. As the COVID-19 pandemic is still active, the impact of policy measures on urological disease will not be apparent until the post-pandemic recovery period. This article describes the changes in urological practice in Australia during the COVID-19 pandemic in the context of the international response.

\section{Methods}

A literature search of PubMed was conducted using search terms "urology," "coronavirus," "COVID-19," and "surgery." This generated 165 articles. The abstracts were reviewed for relevance to the topic of this article, and 33 articles were selected, reviewed in depth, and information synthesised along with relevant government, surgical college, and urological society policy documents for the writing of this article.

\section{Results and Discussion}

\section{Elective Surgery Cancellations}

On March 26, 2020, all elective surgery in Australia, with the exception of category A (within 30 days) and urgent category B (within 90 days), was suspended in an attempt to prepare for a COVID-19 related surge in demand for health care resources[4]. This was swiftly followed by the Urological Society of Australia and New Zealand (USANZ) guidelines for urological prioritisation[5]. The Board encouraged shared decision-making with patients and consideration for individual hospital/health district/ country/state and territory health care resources. Surgical guidelines are summarised in Table 1. These guidelines were intended to provide urologists and their patients with a framework of priority. They empowered the decision to operate where appropriate given the risk of multiple contacts, whilst reassuring patients of the urological safety to defer. A recent systematic review compared 15 guidelines and recommendations for urology care during the pandemic[6]. The European Association of Urology (EAU) was the only other international urological group to publish urological guidelines on practice during the pandemic, with all other guidelines being single expert opinion[7]. A comparison of the USANZ and EAU guidelines is summarised in Table 1.

The guidelines reflect not only the existing differences between Australian and European urological practices but also the varied impact of the pandemic in these regions. For example, the Australian guidelines did not 


\section{TABLE 1.}

Summary of the USANZ and EAU guidelines for urological prioritisation during the COVID-19 pandemic

\begin{tabular}{|c|c|c|}
\hline $\begin{array}{l}\text { Condition } \\
\text { Operation }\end{array}$ & Consider proceeding with surgery & Consider deferral of surgery \\
\hline Testicular Cancer & $\begin{array}{l}\text { USANZ } \\
\text { - Inguinal orchidectomy as planned } \\
\text { - RPLND for progressive mass post chemotherapy } \\
\text { EAU } \\
\text { - Inguinal orchidectomy in } 1-2 \text { days } \\
\text { - RPLND for progressive mass post chemotherapy } \\
\text { within }<6 \text { weeks } \\
\text { - Stage } \geq \text { IIB seminoma or NSGCT treat within } \\
<24 \text { hours }\end{array}$ & $\begin{array}{l}\text { USANZ } \\
\text { - Slowly growing mature teratoma } \\
\text { EAU } \\
\text { - Stage } 1 \text { seminoma for AS }\end{array}$ \\
\hline
\end{tabular}

\begin{tabular}{|c|c|c|}
\hline $\begin{array}{l}\text { Renal Cancer } \\
\text { Transplant }\end{array}$ & $\begin{array}{l}\text { USANZ } \\
\text { - RCC }>7 \mathrm{~cm} \text { as planned } \\
\text { - RCC complicated by venous thrombus } \\
\text { as planned } \\
\text { - Upper tract UCC as planned } \\
\text { EAU } \\
\text { - T3 within }<6 \text { weeks } \\
\text { - High grade UCC within }<6 \text { weeks }\end{array}$ & $\begin{array}{l}\text { USANZ } \\
\text { - Immunotherapy/chemotherapy with delayed } \\
\text { cytoreductive nephrectomy in metastatic RCC } \\
\text { setting } \\
\text { EAU } \\
\text { - Renal mass }<4 \text { cm defer by } 6 \text { months } \\
\text { - T1b-T2 RCC within } 3 \text { months } \\
\text { - Low risk UCC up to } 3 \text { months } \\
\text { - Cadaveric renal transplant up to } 3-4 \text { months (case } \\
\text { by case discussion) } \\
\text { - Living donor up to } 6 \text { months }\end{array}$ \\
\hline Prostate Cancer & $\begin{array}{l}\text { USANZ } \\
\text { - High risk (select Gleason 8-10) as planned } \\
\text { EAU } \\
\text { - High risk post radiation within } 3 \text { months with } \\
\text { immediate neoadjuvant ADT }\end{array}$ & $\begin{array}{l}\text { USANZ } \\
\text { - Intermediate and some high-risk cancers with initial } \\
\text { ADT and deferred definitive treatment } \\
\text { - Low risk with active surveillance } \\
\text { EAU } \\
\text { - Low risk postpone for } 6-12 \text { month and AS defer } \\
\text { for } 6 \text { months } \\
\text { - Intermediate risk to after pandemic } \\
\text { - High risk treat within } 3 \text { months or postpone until } \\
\text { after pandemic (anxious patient or N1 disease, } \\
\text { consider ADT and EBRT as alternative) }\end{array}$ \\
\hline Bladder Cancer & $\begin{array}{l}\text { USANZ } \\
\text { - Surveillance CE +/- TURBT for high-risk NMIBC only } \\
\text { (CIS and G3T1) } \\
\text { EAU } \\
\text { - Grade >cT1 treat within } 6 \text { weeks } \\
\text { - MIBC treat within } 3 \text { months (consider omitting } \\
\text { neoadjuvant chemo in T2/T3 disease) } \\
\text { - Metastatic within } 6 \text { weeks (adjuvant } \\
\text { chemotherapy if } \mathrm{N}+\text { ) }\end{array}$ & $\begin{array}{l}\text { USANZ } \\
\text { - Neoadjuvant chemotherapy and delayed cystectomy } \\
\text { for MIBC (after discussion with medical oncology) } \\
\text { EAU } \\
\text { - Low grade surveillance defer by } 6 \text { months } \\
\text { - High grade surveillance by } 3 \text { months } \\
\text { - Refractory CIS by up to } 3 \text { months } \\
\text { - MIBC if palliative consider only radiation and } \\
\text { chemotherapy }\end{array}$ \\
\hline
\end{tabular}

ADT: androgen deprivation therapy; AS: active surveillance; CE: cystoscopy; CIS: carcinoma in situ; IDC: indwelling catheter; ISC: intermittent self-catheterisation; MIBC: muscle invasive bladder cancer; MRI: magnetic resonance imaging; NMIBC: non-muscle invasive bladder cancer; NSGCT: non-seminomatous germ cell tumour; PIRADS: Prostate Imaging-Reporting and Data System; RCC: renal cell carcinoma; RPLND: retroperitoneal lymph node dissection; TURBT: transurethral resection of bladder tumour. 


\section{TABLE 1.}

Summary of the USANZ and EAU guidelines for urological prioritisation during the COVID-19 pandemic, Cont'd

\begin{tabular}{|c|c|c|}
\hline $\begin{array}{l}\text { Condition } \\
\text { Operation }\end{array}$ & Consider proceeding with surgery & Consider deferral of surgery \\
\hline Macroscopic Haematuria & $\begin{array}{l}\text { USANZ } \\
\text { - Diagnostic CE if abnormal radiology or cytology } \\
\text { EAU } \\
\text { - Clot retention then within } 24 \text { hours }\end{array}$ & $\begin{array}{l}\text { USANZ } \\
\text { - Diagnostic CE if normal investigations } \\
\text { (delay for } 1-2 \text { months) } \\
\text { EAU } \\
\text { - Diagnostic CE up to } 6 \text { weeks if not in retention }\end{array}$ \\
\hline Prostate Biopsies & $\begin{array}{l}\text { USANZ } \\
\text { - PIRADS } 4 / 5 \text { on MRI } \\
\text { EAU } \\
\text { - MRI showing locally advanced or highly } \\
\text { symptomatic }\end{array}$ & $\begin{array}{l}\text { USANZ } \\
\text { - PIRADS }<4 \text { on MRI } \\
\text { - Protocol based AS evaluation } \\
\text { EAU } \\
\text { - Until after pandemic without MRI or not suspicious } \\
\text { for locally advanced/highly symptomatic }\end{array}$ \\
\hline TURP & $\begin{array}{l}\text { USANZ } \\
\text { - Chronic or acute urinary retention not } \\
\text { suitable for IDC or ISC }\end{array}$ & $\begin{array}{l}\text { USANZ } \\
\text { - IDC or ISC where possible } \\
\text { EAU } \\
\text { - IDC or ISC and postpone for } 6 \text { months }\end{array}$ \\
\hline Endourology & $\begin{array}{l}\text { USANZ } \\
\text { - Symptomatic stones as planned } \\
\text { - Obstructed or infected kidney as planned } \\
\text { - Stent in situ as planned } \\
\text { EAU } \\
\text { - Obstructed or infective kidney as planned }\end{array}$ & $\begin{array}{l}\text { USANZ } \\
\text { - Non-obstructing ureteric or renal stones } \\
\text { EAU } \\
\text { - Non-obstructing renal stones for }>6 \text { months } \\
\text { - Non-obstructing ureteric stones for } 3-4 \text { months } \\
\text { (manage renal colic with pain relief, avoiding } \\
\text { NSAIDs where possible) } \\
\text { - Stent in situ for }>6 \text { months (after pandemic) }\end{array}$ \\
\hline Scrotal & $\begin{array}{l}\text { USANZ } \\
\text { - Torsion as planned } \\
\text { EAU } \\
\text { - Torsion as planned }\end{array}$ & \\
\hline
\end{tabular}

\begin{tabular}{|l|l|}
\hline USANZ \\
- Penile as planned \\
Trauma & - Urethral as planned \\
& EAU \\
\hline & Penile as planned \\
\hline
\end{tabular}

ADT: androgen deprivation therapy; AS: active surveillance; CE: cystoscopy; CIS: carcinoma in situ; IDC: indwelling catheter; ISC: intermittent self-catheterisation; MIBC: muscle invasive bladder cancer; MRI: magnetic resonance imaging; NMIBC: non-muscle invasive bladder cancer; NSGCT: non-seminomatous germ cell tumour; PIRADS: Prostate Imaging-Reporting and Data System; RCC: renal cell carcinoma; RPLND: retroperitoneal lymph node dissection; TURBT: transurethral resection of bladder tumour. 
recommend deferring endourological procedures for patients with ureteric stents in situ as the EAU guidelines suggested. As Europe is the second most affected continent, with 230 COVID-19 deaths per million people compared with Australia's 10 per million, the differences in guidelines reflect the differing degree of health care resource demand. From Tuesday, 28 April 2020, elective surgery restrictions were eased in Australia. However, with a substantial second wave of COVID-19 cases in Victoria towards the end of June, elective surgery restrictions were reintroduced on Thursday, 16 July 2020. With large fluctuations in case numbers, further reviews into scope of elective operating are likely before the recovery from the pandemic can begin.

Additionally, the future challenge of post-COVID waitlist reduction and health impacts from ongoing untreated disease is not fully realised. One study modelled the proportion of elective surgery that would be cancelled or postponed during the 12 weeks of peak disruption[8]. They found that a global total of 2.95 million urological surgeries will be postponed during this period. In the United Kingdom for example, based on an average cost of $£ 4000$ per operation, it would cost over $£ 2$ billion to clear the backlog. Additional considerations such as costs of complicated disease progression, deaths due to untreated disease, and a differently structured health care system are other post-COVID surgical challenges yet to be completely quantified.

\section{Operative COVID Precautions}

Once the decision is made that it is safe and appropriate to operate, operative measures are implemented to further optimise safety and mitigate infection risk.

\section{Preoperative Workup}

The Royal Australasian College of Surgeons (RACS) has published a rapid review of literature and recommendations for preoperative COVID-19 assessment [9]. If high-risk features (viral symptoms and high-risk contacts) are identified on history, patients are recommended to have reverse transcription-polymerase chain reaction (RT-PCR) test to diagnose SARS-CoV-2, and in patients over the age of 70 years, a CT scan of the chest is also recommended. The RT-PCR test is $80 \%$ to $100 \%$ sensitive compared with the $60 \%$ to $70 \%$ sensitivity of nasopharyngeal and oropharyngeal testing[10]. RACS recommends that surgery required within 24 hours in high-risk patients should proceed, with surgical staff wearing full personal protective equipment and taking appropriate intraoperative precautions, especially for potential aerosol-generating procedures (AGPs). The patient is then to be isolated postoperatively and tested for SARS-CoV-2 infection when possible. RACS does not endorse testing asymptomatic patients with no high-risk features before surgery. This is mirrored by the American Centers for Disease Control[11]. However, given that $5 \%$ to $80 \%$ of COVID-19 patients are asymptomatic carriers, one systematic review article recommends testing all preoperative patients if the testing capacity is available[12]. Recommendations for preoperative testing will be dictated by local health care providers and testing resources, turnaround time, and acuity of procedure must be balanced with the theoretical risk of an asymptomatic carrier exposing theatre staff to the virus.

\section{Safe Minimally Invasive Surgery}

Several studies analysing viral shedding have not detected SARS-CoV-2 in urine[13-15]. However, one Chinese study detected SARS-CoV-2 RNA in the urine of 4 COVID-19 patients requiring hospitalisation out of a total of 58 patients in the cohort[16]. Viral particles have also been demonstrated in COVID-19 patient blood samples[17]. Consequently, non-urgent cystoscopies should be deferred and extra caution taken to minimise trauma during procedures. One American review on operative adjustments during the pandemic suggests the use of disposable ureteroscopes to further reduce the risk of contamination[12]. Given the highest risk of aerosolization is during intubation and extubation, the Anaesthesia Patient Safety Foundation has further recommended that when possible, ureteric stents should be inserted under sedation[18]. During the pandemic, and particularly within areas of high case numbers and stretched health care resources, added consideration of nephrostomy tubes in the acute setting is also advised. However, this remains contentious. The American Society of Anaesthesiologists states that laryngeal mask airway may actually increase the risk of aerosolization of SARS-CoV-2 in the setting of high airway pressures and leakage around the mask[19]. Furthermore, although monitored anaesthesia care avoids intubation and extubation, it could potentially require the anaesthesia provider to be closer to the patient's airway and be a potentially greater risk if there is any issue requiring manual bagging or unplanned intubation. The society acknowledges that, because there is a lack of validated studies, this is expert opinion rather than practice guidelines.

AGPs can generate bioaerosols that contain viral materials, which should be considered a potential source of disease transmission[20]. RACS recommends using lower energy ablation devices, where possible, to produce fewer or no surgical plumes thus mitigating risk. All bioaerosols should be trapped and treated as biohazards. For laparoscopic procedures, the pneumoperitoneum should be maintained at a lower pressure to reduce the risk of gas leak. On desufflation, gas should be vented via an appropriate filter and capture device. Despite a lack of firm evidence to prove SARS-CoV-2 particle 
transmission through aerosolization, international guidelines also suggest similar precautionary measures. A review of the international guidelines into AGPs during the pandemic suggested steps to reduce the risk of aerosolization during release of pneumoperitoneum and diathermy until more information is available[12]. Most guidelines suggest frequent suctioning of smoke in the pneumoperitoneum, avoidance of air leaks around ports and during instrument transfers, and care in removing ports, especially when pneumoperitoneum is still established. Other techniques to consider include using balloon ports or trocars that can be secured to avoid pneumoperitoneum leaking at the port sites.

Ultimately, the choice of procedure should not compromise the patient outcomes. Therefore, laparoscopy and robotics must be used when indicated. The surgeon should carefully weigh the pros and cons of each approach. In addition to reducing the exposure of the patient and health care workers, operating time, blood loss, length of hospital stay, and risk of short- and long-term complications should be considered.

\section{Use of Telehealth}

Telemedicine allows the provision of health care remotely using electronic communication tools[21]. Telehealth is aimed at helping protect health care professionals, their staff, and patients from unnecessary risk of infection by minimising contacts. Large international prospective studies comparing telehealth with traditional face-to-face consultations have shown clinical equivalency, safety, and acceptable patient satisfaction in both prostate cancer and endourology settings[22,23]. Although these benefits have been well established, barriers include the reluctance of patientsparticularly the elderly-to use the technology, costeffectiveness, and security of communication links regarding personal (including health) data[24]. As a result, Australia has been slow to embrace telehealth with uptake mainly restricted to remote communities for certain medical specialties such as nephrology. Telehealth has been largely underused by urologists in Australia. However, to facilitate continued safe health care, the Australian government has fast tracked the use of telehealth by providing clinicians with subsidised telehealth equipment from 13 March[24]. Similar provisions have been made in the United Kingdom[25]. This allows clinicians to claim for consultations made via telehealth, which was previously not a widely available option. Ethical considerations need to be made for delivering cancer diagnoses remotely, and judicious individualised patient care is paramount. The absence of cancer specialist nurses and increased isolation may worsen the impact of a cancer diagnosis delivered via telehealth. However, as the medical industry adapts to the pandemic, telehealth may persist and become routine practice because it is convenient, it allows increased access to regional patients, and it has proven efficacy. With increasing use, streamlined platforms will no doubt become available. Furthermore, particularly within Australia, virtual departmental meetings, multidisciplinary team meetings, and morbidity and mortality meetings offer similar benefits and are becoming increasingly popular.

\section{Education and Training}

The COVID-19 pandemic has had a significant impact on national and international urological education and training. The USANZ annual scientific meeting and all individual state meetings have been cancelled in Australia along with the American Urological Association annual meeting. Other international meetings such as the European Association of Urology Congress and the Société Internationale d'Urologie Congress have moved to virtual platforms. With research resources shifted to COVID-19, specifically vaccination development, the slowing of urological development is inevitable. Clinically, the cancellation of training examinations, freeze on rotations, and elective surgery restrictions have blunted surgical experience and teaching. The effect has rippled through all training doctor positions from clinical medical student to advanced trainee, and uncertainty remains with respect to training positions for future years. Similar disruptions have been observed in the UK and Singapore, with all undergraduate clinical rounds being cancelled and all teaching activities (for residents and undergraduates) switched to the online platforms[26]. This will not only impact trainee clinical development but also increase junior doctor stress and burnout. With social distancing laws and community lockdowns increasing individual isolation, the added employment uncertainty raises significant concern for the mental health of junior doctors.

\section{Australian Rural Experience}

Australia is an expansive country, with $29 \%$ of the population living in rural or remote regions[27]. These areas are often hundreds of kilometres from metropolitan centres and are therefore reliant on under-resourced health care services. After the country weathered the largest bushfire disaster regional Australia has ever experienced, COVID-19 posed an additional challenge to communities that were just starting to recover.

Regional and remote urological care in Australia is largely self-sufficient with transfer to larger centres generally reserved for critical deterioration or where multiple subspecialty services are required. Many of these communities rely on fly-in/fly-out urologists, who also provide emergency surgical support whilst 
on site. As a result of elective surgical cancellations, urologists were flying in more sparingly. Emergency urological procedures were therefore being attended to by resident general surgeons or required atypical metropolitan transfer. This has led to increased time to definitive treatment such as scrotal exploration in the event of suspected torsion, and to greater reliance on interventional radiology for acute renal decompression in the event of obstructive uropathy.

Furthermore, all Australians have exhibited more restrained health care practices. For example, data from the Cancer Council have shown that there were 144982 fewer mammograms and 443935 fewer cervical screening tests between January and June 2020, and 144379 fewer bowel screening tests returned from January to July, compared with previous years[28]. Similarly, patients are presenting later with haematuria, and those on active surveillance for urological cancers are more likely to delay routine surveillance appointments to avoid contacts. This challenge is exaggerated in regional and remote communities, particularly amongst Indigenous Australians, where follow-up procedures and compliance are already fragile.

However, as a result of geographical isolation, these areas were largely unaffected by COVID-19, with infection rates very low and early travel restrictions preventing spread of the virus from metropolitan areas.
Most rural urological services have since returned to routine practice, with the pandemic highlighting the longstanding health care inequalities in these regions and challenging policy makers to provide solutions.

\section{Conclusions}

The COVID-19 pandemic is the greatest current challenge facing health care worldwide. Amidst elective surgery restrictions, novel preoperative testing procedures, and intraoperative precautions, providing safe and appropriate urological care is a major challenge. Australia is fortunate to have successfully contained the pandemic and therefore to have had minimal disruptions. This can be attributed to fostering strong clinician-patient partnerships with the use of telehealth and swiftly implementing policies and procedures to minimise the risk of surgery on pandemic progression to provide optimal urological care. Invariably, urological academic and clinical development is challenging during the pandemic and insight into mental health challenges for frontline workers needs to be considered and managed. This review was entirely derived from expert opinion articles, and further research into the virus including promising vaccination programs will be key to bringing the world safely through the pandemic with post-pandemic recovery likely being the next challenge. 


\section{References}

1. What you need to know about coronavirus (COVID-19): Australian Government; 2020 Available at: https://www.health.gov.au/news/ health-alerts/novel-coronavirus-2019-ncov-health-alert/what-youneed-to-know-about-coronavirus-covid-19. Accessed February 9, 2021.

2. World Health Organisation (WHO) Director-General's opening remarks at the media briefing on COVID-19 - 11 March 2020. Available at: https://www.who.int/dg/speeches/detail/who-director-general-sopening-remarks-at-the-media-briefing-on-covid-19---11-march-2020. Accessed February 9, 2021.

3. Coronavirus disease (COVID-19) 2020. Available at: https://www.who. int/docs/default-source/coronaviruse/situation-reports/20200807covid-19-sitrep-200.pdf?sfvrsn=2799bc0f_2. Accessed February 9, 2021.

4. Scott Morrison. Elective Surgery. Media release; March 25, 2020. Available at: https://www.pm.gov.au/media/elective-surgery. Accessed February 9, 2021.

5. Urological Society of Australia and New Zealand (USANZ). Urological prioritisation during COVID-19 2020. March 25, 2020. Available at: https://www.usanz.org.au/news-updates/our-announcements/ usanz-announces-guidelines-urological-prioritisation-covid-19. Accessed February 9, 2021.

6. Heldwein FL, Loeb S, Wroclawski ML, Sridhar AN, Carneiro A, Lima FS, et al. A systematic review on guidelines and recommendations for urology standard of care during the COVID-19 Pandemic. Eur Urol Focus.2020;6(5):1070-1085.

7. Ribal MJ, Cornford P, Briganti A, Knoll T, Gravas S, Babjuk M, et al. European Association of Urology Guidelines Office Rapid Reaction Group: an organisation-wide collaborative effort to adapt the European Association of Urology guidelines recommendations to the coronavirus disease 2019 era. Eur Urol.2020 Jul;78(1):21-28. Published online 2020 Apr 27. doi: 10.1016/j.eururo.2020.04.056.

8. COVIDSurg Collaborative. Elective surgery cancellations due to the COVID-19 pandemic: global predictive modelling to inform surgical recovery plans. Br J Surg.2020 0ct;107(11):1440-1449. doi: 10.1002/ bjs.11746. Epub 2020 Jun 13.

9. Royal Australasian College of Surgeons. Guidelines on the preoperative diagnostic workup for COVID-19 2020. Available at: https://www. surgeons.org/-/media/Project/RACS/surgeons-org/files/news/ covid19-information-hub/Guidelines-on-the-Preoperative-DiagnosticWorkup-for-COVID-19pdf?rev=6da3bef72d4f42bc8727a3ef43776dc5 \&hash=52DC2A4B1F7B2B88F1F789F949D77C12. Accessed February 9, 2021.
10. Yang Y, Yang M, Shen C, Wang F, Yuan J, Li J, et al. Evaluating the accuracy of different respiratory specimens in the laboratory diagnosis and monitoring the viral shedding of 2019-nCoV infections. medRxiv; 2020. doi: https://doi.org/10.1101/2020.02.11.20021493.

11. Centers for Disease Control and Prevention. Overview of Testing for SARS-CoV-2.: Centers for Disease Control and Prevention; 2020. Available at: https://www.cdc.gov/coronavirus/2019-ncov/hcp/ testing-overview.html?CDC_AA_refVal=https\%3A\%2F\%2Fwww. cdc.gov\%2Fcoronavirus\%2F2019-ncov\%2Fhcp\%2Fclinical-criteria. html. Accessed February 9, 2021.

12. Steward JE, Kitley WR, Schmidt CM, Sundaram CP. Urologic surgery and COVID-19: how the pandemic is changing the way we operate. J Endourol.2020;34(5):541-549.

13. Wölfel R, Corman VM, Guggemos W, Seilmaier M, Zange S, Müller MA, et al. Virological assessment of hospitalized patients with COVID2019. Nature.2020;581(7809):465-469.

14. Yu F, Yan L, Wang N, Yang S, Wang L, Tang Y, et al. Quantitative detection and viral load analysis of SARS-CoV-2 in infected patients. Clin Infect Dis.2020;71(15):793-798.

15. Lo IL, Lio CF, Cheong HH, Lei Cl, Cheong TH, Zhong X, et al. Evaluation of SARS-CoV-2 RNA shedding in clinical specimens and clinical characteristics of 10 patients with COVID-19 in Macau. Int J Biol Sci.2020;16(10):1698-1707.

16. Ling Y, Xu SB, Lin YX, Tian D, Zhu ZQ, Dai FH, et al. Persistence and clearance of viral RNA in 2019 novel coronavirus disease rehabilitation patients. Chin Med J (Eng/).2020;133(9):1039-1043.

17. Kwon SY, Kim EJ, Jung YS, Jang JS, Cho NS. Post-donation COVID-19 identification in blood donors. Vox Sang.2020 Nov;115(8):601-602. doi: 10.1111/vox.12925. Epub 2020 Apr 21.

18. Calabrese G. Update on biological risk for anesthetists taking care of patients affected by SARS-CoV-2, COVID-19. Colomb J Anesthesiol.2020;48(3):138-144.

19. American Society of Anesthesiologists. COVID FAOs: Clinical care 2020. Available at: https://www.asahq.org/about-asa/governanceand-committees/asa-committees/committee-on-occupationalhealth/coronavirus/clinical-faqs. Accessed February 9, 2021.

20. Royal Australasian College of Surgeons. Guidelines for safe surgery: open versus laparoscopic 2020. Available at: https://umbraco. surgeons.org/media/5214/2020-04-15-recommendations-on-safesurgery-laparoscopic-vs-open.pdf. Accessed February 9, 2021. 
21. Hollander JE, Carr BG. Virtually Perfect? Telemedicine for Covid-19. N Engl J Med.2020;382(18):1679-1681.

22. Connor MJ, Miah S, Edison MA, Brittain J, Smith MK, Hanna M, et al. Clinical, fiscal and environmental benefits of a specialistled virtual ureteric colic clinic: a prospective study. BJU Int.2019;124(6):1034-1039.

23. Miah S, Dunford C, Edison M, Eldred-Evans D, Gan C, Shah TT, et al. A prospective clinical, cost and environmental analysis of a clinician-led virtual urology clinic. Ann R Coll Surg Engl.2019;101(1):30-34.

24. Tachakra S, Wang X, Istepanian RS, Song Y. Mobile e-health: the unwired evolution of telemedicine. Telemedicine Journal and E-health.2003;9(3):247-257.

25. Australian Government Department of Health. Providing health care remotely during COVID-19 2020. Available at: https://www.health. gov.au/news/health-alerts/novel-coronavirus-2019-ncov-health-alert/ coronavirus-covid-19-advice-for-the-health-and-aged-care-sector/ providing-health-care-remotely-during-covid-19\#: :text=From $\% 20$ 13\%20March\%20to\%2030,patients\%20and\%20health\%20care\%20 providers. Accessed February 9, 2021.
26. Connor MJ, Winkler M, Miah S. COVID-19 pandemic - is virtual urology clinic the answer to keeping the cancer pathway moving? BJU Int.2020;125(6):E3-E4.

27. Australian Institute of Health and Welfare 2019. Rural \& remote health. Cat. no. PHE 255. Canberra: AlHW. Available at: https://www. aihw.gov.au/reports/rural-remote-australians/rural-remote-health. Accessed February 11, 2021.

28. Australian Institute of Health and Welfare 2020. Cancer screening and COVID-19 in Australia. Cat. no. CAN 136. Canberra: AlHW. Available at: https://www.aihw.gov.au/reports/cancer-screening/cancerscreening-and-covid-19-in-australia. Accessed February 11, 2021. 